\title{
INFLUENCE OF AGE AND GENDER ON THE STRENGTH OF BLOOD VESSELS
}

\author{
Zyta Kuzborska ${ }^{1}$
}

\begin{abstract}
This article examines the effects of cardiovascular diseases that alter the diameter, wall thickness, and length of blood vessels. Depending on form and size of the damage, blood flow velocity, blood pressure, and stresses are affected in areas of diseased blood vessels. Through stimulating the deviations in the geometric shape of a blood-vessel wall, local blood pressure and stresses can arise from flow variation of blood vessels. This rise affects the blood-vessel wall and causes critical stresses likely to produce fissures in the blood vessels. It was found, that blood vessel pathology could cause blood flow velocity to increase up to 2.2 times and local blood pressure up to 3.4 times, and that human aging may have a significant influence on blood-vessel strength.
\end{abstract}

UDC Classification: 616.1, 612.1, 531, 532, 62 DOI: http://dx.doi.org/10.12955/cbup.v4.839

Keywords: blood vessel, flow, local blood pressure, stress.

\section{Introduction}

Cardiovascular diseases are the main cause of human disability and death in the world, including Lithuania (Laucevičius et al. 2013; Roger et al., 2012; Rosamond et al., 2007). According to literature, every third person dies of cardiovascular system dysfunction that causes rupture of blood vessels (atherosclerosis causes heart attacks and strokes; Petrulionienė \& Apanavičiené, 2010).

Cardiovascular diseases affect the diameter, wall thickness, and length of blood vessels in various ways (Mariūnas \& Kuzborska, 2011; Wang \& Parker, 2004; Hyun Soo Kim, Kyoung, \& Cho, 2013). Depending on the type and extent of the pathology, blood flow rate, blood pressure, and stresses will vary in areas affected by diseased blood vessels (Mariūnas \& Uzdilaite, 2006). When there is a particular variation in blood-vessel wall geometry, local blood pressure and stresses increase because of flow variation in the blood vessel (Mariūnas, Kuzborska, \& Šešok, 2013; Lantz, Renner, \& Karlsson, 2011). This affects the blood-vessel wall and causes critical stresses that could lead to fissures in the blood vessel.

Atherosclerosis can be diagnosed by various diagnostic and experimental methods, for example, the ultrasonic double-scanning duplex method (Panniera, Avolio, Hoeksc, Mancia, \& Takazawa, 2002; Pickering, 2002); as well as digital methods, e.g., as the finite element method (Taylor \& Steinman, 2005). In measuring blood pressure, an increase of general blood pressure is identifiable, but it is difficult to determine blood pressure in stenosis areas, because these areas involve local blood pressure, which could vary somewhat from total pressure (Vignon-Clementel, Figueroa, Jansen, \& Taylor, 2010).

Patients with atherosclerosis blood pressure could be monitored using experimental methods. However, the dependence of blood-vessel-wall stresses on the stenosis value makes it practically impossible. Experimental diagnostic research requires sophisticated equipment (Meola \& Petrucci, 2008; Birgit Kantor et al. 2009) and inaccuracies occur when determining blood pressure using this approach. However, digital methods can model the process in stenosis areas to varying degrees within a wide scope (Steele, Wan, Ku, Hughes, \& Taylor, 2003; Taylor \& Draney, 2004; Vignon \& Taylor, 2004; Cecelja \& Chowienczyk, 2012) to obtain sufficiently accurate results. These digital methods could append results from the experimental method and provide more detailed information about blood flow, blood pressure, and stresses in stenosis areas.

Digital methods make it possible to evaluate wider complex effects on variations of blood-flowvelocity, blood pressure, and stresses in stenosis areas, including assessing patient's age and gender, and the degree of blood-vessel pathology.

This research focuses on blood-vessel impairment caused by disease (atherosclerosis) as well as the associated blood flow processes that depend on the scale of impairment, age, gender, and mechanical characteristics of the blood vessel.

\footnotetext{
${ }^{1}$ Zyta Kuzborska, Department of Nursing, Faculty of Health Care, Vilniaus kolegija University of Applied Sciences, and Department of Biomechanics, Faculty of Mechanics, Vilniaus Gediminas Technical University, Vilnius, Lithuania, zyta.kuzborska@ gmail.com
} 
The study aims to examine blood flow characteristics, local blood pressure, and stress distribution in pathologic blood vessels, as well as assess variation in blood vessel mechanics related to a patient's age, gender, and degree of blood vessel pathology.

\section{Methodology}

The set aims were achieved through analytical, experimental, digital, and statistical research methods. Blood flow, blood pressure, and stresses relating to the different pathologic states of the blood vessels were modelled using a method of finite elements (ANSYS software package).

With the intention of determining stresses, blood pressure, and flow rate in the pathologic blood vessels, atherosclerosis with single symmetric stenosis, symmetric double stenosis, and asymmetric stenosis (impaired from 25\% to 95\%) were analyzed incorporating Navier-Stokes equations.

For calculations, blood flow in the vessels was elected as incompressible Newtonian fluid, with the following properties: average statistical blood flow velocity in systolic pressure $(v)$ of $0.5 \mathrm{~m} / \mathrm{s}$; dynamic viscosity of blood $(\mu)$ of $0.0035 \mathrm{~kg} / \mathrm{m}$; blood density $(\rho)$ of $1060 \mathrm{~kg} / \mathrm{m}^{3}$. Blood flow is impulsive in nature and cycle duration was given as $0.8 \mathrm{~s}$, where $0.4 \mathrm{~s}$ was systole, i.e., blood supply, and $0.4 \mathrm{~s}$ diastole. To describe blood flow patterns, sinusoidal law was used (Mariūnas \& Uzdilaite, 2006).

The following assumptions will be used in the work: blood is a Newtonian fluid; blood dynamic viscosity $(\mu)$ is constant (Mandal, 2005); when there is laminar blood flow, Reynolds number $(R e)$ is 1700; blood vessel has linear elasticity characteristic $(E)$ and this is constant (Milnor, 2009); stationary blood flow in the segment is not pulse-like although the blood system almost always is pulse-like (Long, 2001); the chosen blood vessels are free of mechanical defects and wall thickness is the same in all; there is normal stress in the blood-vessel wall and shear stress is a second-order tensor and not evaluated.

The blood flow was examined by solving Navier-Stokes equations for equilibrium of Newtonian fluids; Cartesian coordinate system with coordinates ( $\mathrm{x}, \mathrm{y}$, and $\mathrm{z}$ ); and the operator defined in terms of partial derivative operators, according to Milnor (2009), as follows:

$$
\rho\left(\frac{\partial v}{\partial t}+v \nabla v\right)=-\nabla p+\mu \nabla^{2} v+f ; \nabla=i \frac{\partial}{\partial x}+j \frac{\partial}{\partial y}+k \frac{\partial}{\partial z}
$$

The continuous flow equation was:

$$
\frac{\partial u}{\partial x}+\frac{\partial v}{\partial y}+\frac{\partial w}{\partial z}=0
$$

where $\rho$ is the fluid density; $v$ the flow velocity; $\nabla$ the del operator; $\nabla p$ the gradient of pressure of surfaces; $\mu$ the (constant) dynamic viscosity; $f$ other body forces; and $p$ pressure.

The main finite elements of the elastic body matrix Equations (3) and (4) was as follows:

$$
\begin{gathered}
{\left[M_{S}\right]\{\ddot{U}\}+\left[K_{S}\right]\{U\}=\left\{F_{S}\right\}+[R]\{P\}} \\
{\left[M_{f}\right]\{\ddot{P}\}+\left[K_{f}\right]\{U\}=\left\{F_{f}\right\}+\rho_{0}[R]^{T}\{\ddot{U}\}}
\end{gathered}
$$

where $\left[M_{s}\right]$ and $\left[M_{f}\right]$ represent the elasticity matrixes; $\left[K_{s}\right]$ and $\left[K_{f}\right]$ the tightness matrixes; $\{P\}$ and $\{\ddot{P}\}$ the first and second order pressure variation matrices; $[R]$ the connection matrix; $[R]^{T}$ the transpose connection matrix; $\left\{F_{s}\right\}$ and $\left\{F_{f}\right\}$ the forces variation matrices; $\rho_{0}$ density; $P$ pressure, $\{U\}$ and $\{\ddot{U}\}$ the first and second order displacements variation matrices. The $[R]$ matrix unites the impact of the fluid upon an elastic body, i.e., unites Equations 1 and 2 with Equations 3 and 4 (Mariūnas \& Kuzborska, 2011; Mariūnas \& Uzdilaitè, 2006).

In the calculations, the blood-vessel elasticity module $(E)$ was considered to be $4.66 \mathrm{MPa}$, Poisson's ratio (v) was 0.49 , and blood vessel wall density $(\rho) 1100 \mathrm{~kg} / \mathrm{m}^{3}$. The blood-vessel wall was smooth, isotropic, and its strength characteristics did not vary along its length. 
Boundary conditions at the beginning of the blood vessel were determined so that for any determination of arterial systolic pressure, the maximum value would increase consistently from $16 \mathrm{kPa}$ to $27 \mathrm{kPa}$ (120 mmHg to $200 \mathrm{mmHg}$ ).

Blood-vessel strength was tested using the universal strength meter "Titan" (Figure 1), which registered relative blood-vessel elongation. Blood vessels were stretched until they ruptured. Blood vessel stretch length was $100 \pm 0.25 \mathrm{~mm}$ with a diameter of $10 \pm 3 \mathrm{~mm}$. Results were statistically processed using "MatLab" software package.

Age and gender influence on animal blood-vessel strength was examined. Gender of male and female; ages of $6,12,18,24$, and 36 months; and arterial blood vessels of animal origin (thoracic part of the aorta) were used in the research. Approximate average age of pigs was $14.63 \pm 1.13$ months.

\section{Results and Discussion}

To determine stresses in the pathologic blood vessels, atherosclerosis with a single and double plate was analyzed as follows:

- Stenosis in arteries was modelled for degree of impairment ranging from $25 \%$ to $95 \%$.

- A linear pathologic blood-vessel model was developed.

When the blood-vessel diameter stenosis ranged from $25 \%$ to $95 \%$, in the case of single asymmetric stenosis, the relative blood-flow velocity increased from 1.30 to 1.38 times, in case of single symmetric stenosis, it increased 2.07 times, and for double symmetric stenosis, 2.2 times (Figure 2).

The research results showed that variation in blood-flow velocity was caused by damage to the blood vessel shape.

Figure 1: Strength meter "Titan"

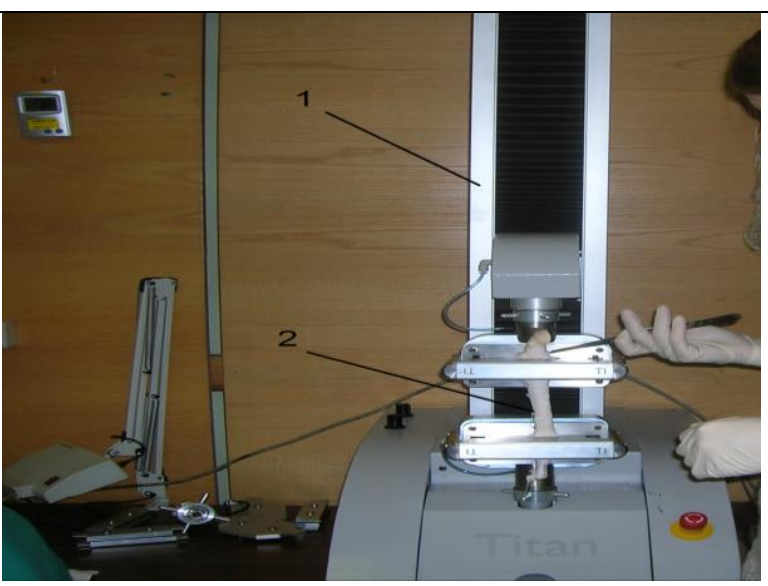

1: strength meter; 2 : sample.

Source: Author

Local blood pressure distribution in the blood vessel (for single asymmetric stenosis, single symmetric stenosis, and double symmetric stenosis) is shown in Figures 3 and 4.

With blood pressure ranging between 16 and $27 \mathrm{kPa}$ and stenosis from $50 \%$ to $95 \%$, the case of single asymmetric stenosis the local blood pressure distribution displayed an increase between 2.58 and 2.80 times, the case of single symmetric stenosis from 2.68 to 2.95 times, and the case of double symmetric stenosis from 3.12 to 3.85 times. The research results indicated that variation of local blood pressure distribution in blood vessels was caused by damage to the blood-vessel shape.

The research results also showed variation in the maximum "von Mises" stress distributions among blood vessels with damage to the blood-vessel shape (Figure 5). The cases of double symmetric stenosis rendered the most concerning results, followed by cases of single symmetric stenosis. 
Figure 2: Relative blood velocity dependence on degree of blood vessel pathology

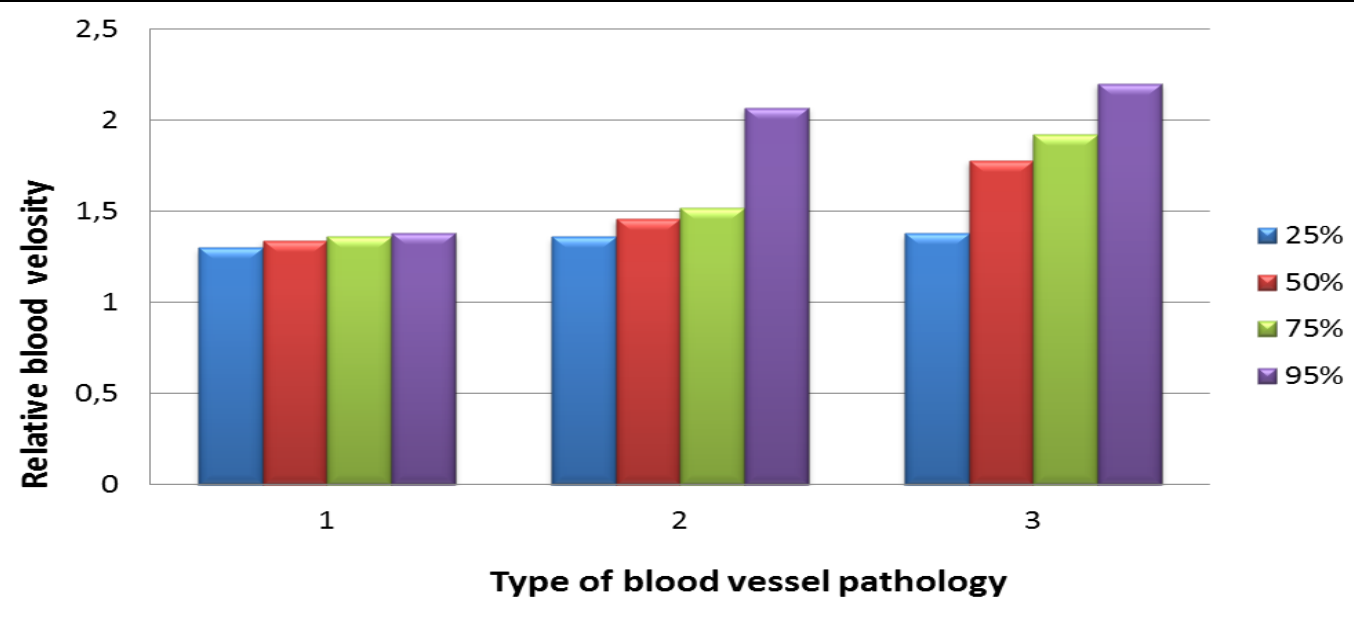

1 - single asymmetric stenosis; 2 - single symmetric stenosis; 3 - double symmetric stenosis.

Source: Author

Figure 3: Local blood pressure distribution in the blood vessel for single asymmetric stenosis, single symmetric stenosis, double symmetric stenosis
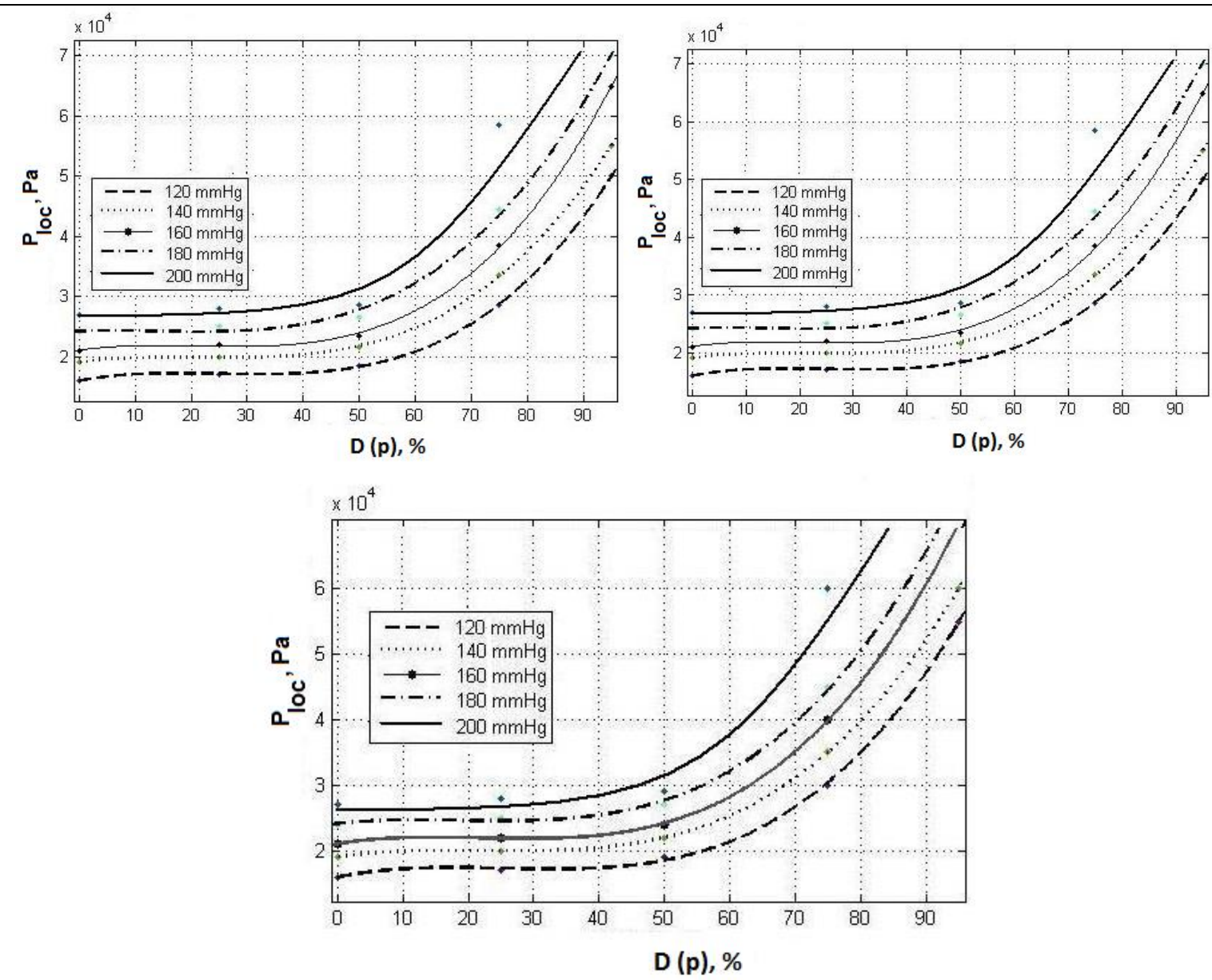

Source: Author 
Figure 4: Maximum local blood pressure distribution in damaged blood vessels

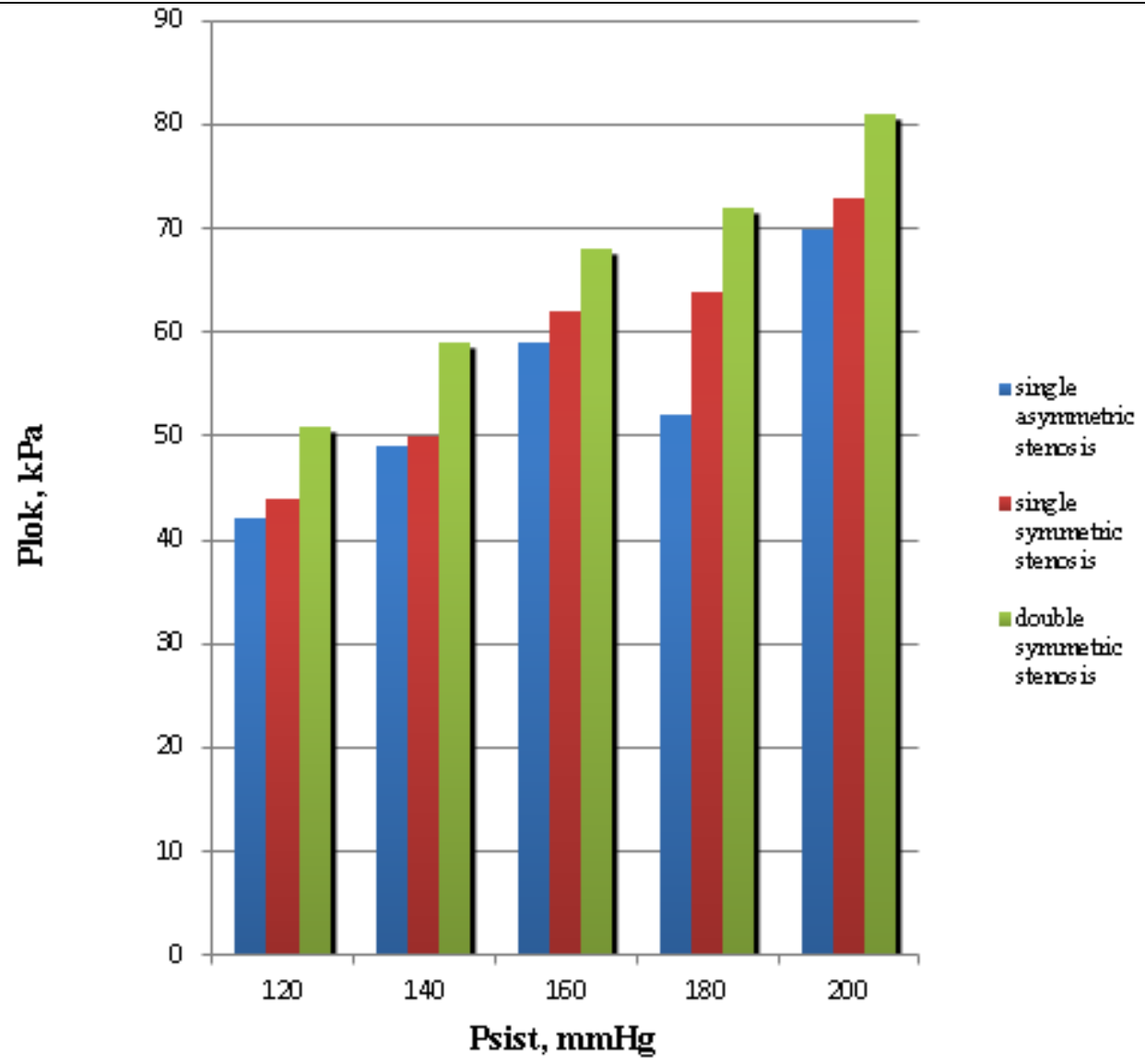

Source: Author

Many scientists analyze changes in the cardiovascular system in relation to atherosclerosis (Mariūnas \& Uzdilaite, 2006; Laucevičius et al. 2013). Research data of blood-vessel strength are reported in scientific literature, but consideration of age and gender difference is lacking in this respect (Balázs, Bognár, Zima, \& Dobránszky, 2008). It is known that decreased elasticity of blood vessels and atherosclerosis occurs with aging and because of this, blood flow velocity, blood pressure, and stresses will vary in areas with stenosis. The results of this study are similar to those found in literature, with indications of an increase in blood-flow velocity up to 2.2 times and local blood pressure up to 3.4 times in areas with stenosis. Therefore, blood vessel fissures may occur, not because of systolic pressure, but from increased local blood pressure. The main influence on local blood pressure was the pathologic state of the blood vessel. The most concerning stenosis type for patient health was the double symmetric stenosis.

Blood vessels of animal origin were used in the experimental research. These were blood vessels of pigs because their biological properties are the closest to human biological characteristics (Michlek, Zyra, \& Lagan, 2013). Age and gender influence on the strength of animal blood vessels was examined. Blood vessels of the thoracic part of the aorta in males and females of the ages between 6 and 36 months were examined.

During the experiment, pressure ranging between $3 \mathrm{~N}$ to $600 \mathrm{~N}$ loads was programed to test for blood vessel stretch in examining the mechanical features of the aorta thoracic section with pressure until the blood vessel ruptured. Figures 6 and 7 show blood-vessel strength features according to load $\left(\mathrm{F}_{\mathrm{N}}\right)$. Obtained results show that blood-vessel strength decreases with age. In males, the blood vessel strength decreased 1.22 times at 12 months, 1.49 times at 18 months, 6.15 times at 24 months, and 9.07 times at 36 months. During examination of female blood vessels, it was found that blood-vessel 
strength decreased 1.19 times at 12 months, 1.46 times at 18 months, 6.46 times at 24 months, and 9.13 times at 36 months.

Figure 5: Maximum "von Mises" stress distribution in the pathologic blood vessel

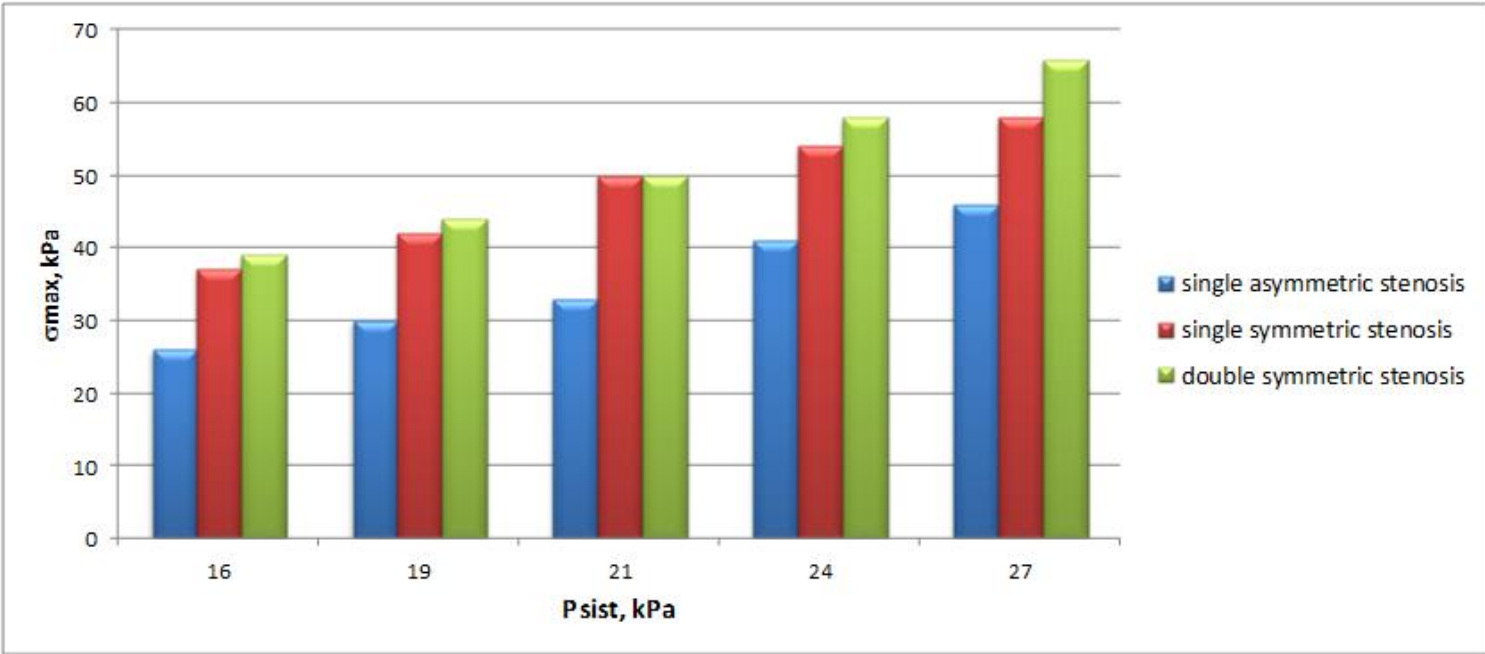

\section{Source: Author}

There are many experimental studies regarding blood vessels of animal origin reported in scientific literature. However, studies of age and gender influence on blood vessel strength are lacking.

The results of this study show that male and female blood-vessel strength decreases with age. The male and female 6-month old blood-vessel strengths were the same, but with increase in age there were slight differences indicated. At 12 months the male blood-vessel strength presented a relative value of 0.82 , compared to that of the female of 0.84 ; at 18 months this value was 0.67 for the male and 0.68 for the female; at 24 months 0.16 for the male and 0.15 the female; and at 36 months 0.10 for the male and 0.11 for the female. Possibly, gender difference has some impact on the blood vessel strength, and aging has a greater influence on blood vessel strength, as the increase in the ages examined in this study corresponded to blood vessel strength decreases of up to 9 times (Figure 7).

Figure 6: Animal blood-vessel breaking-force dependences regarding relative elongation in males (a) and females (b)

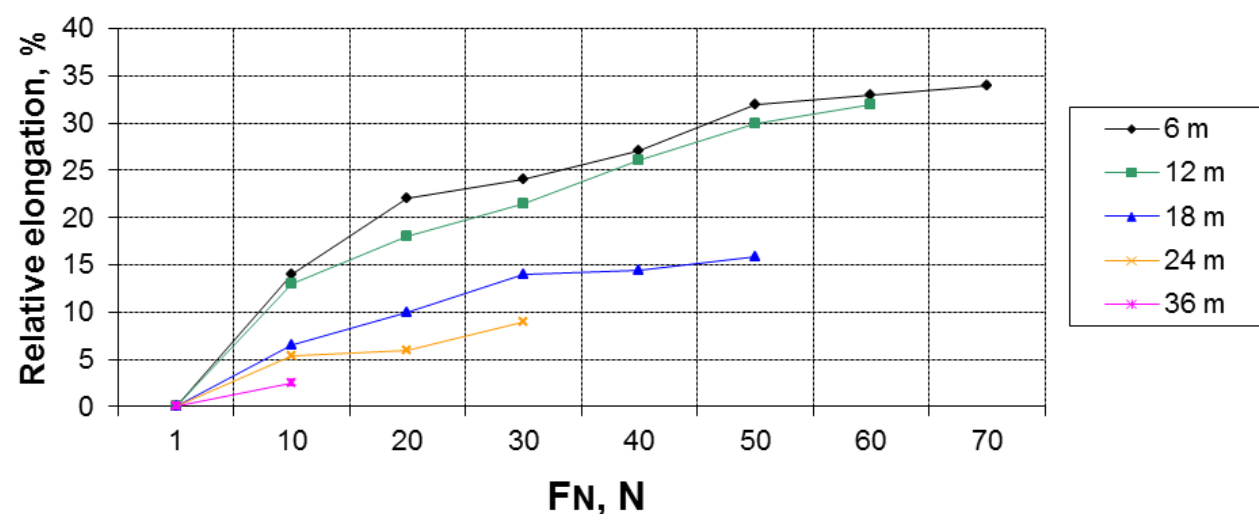




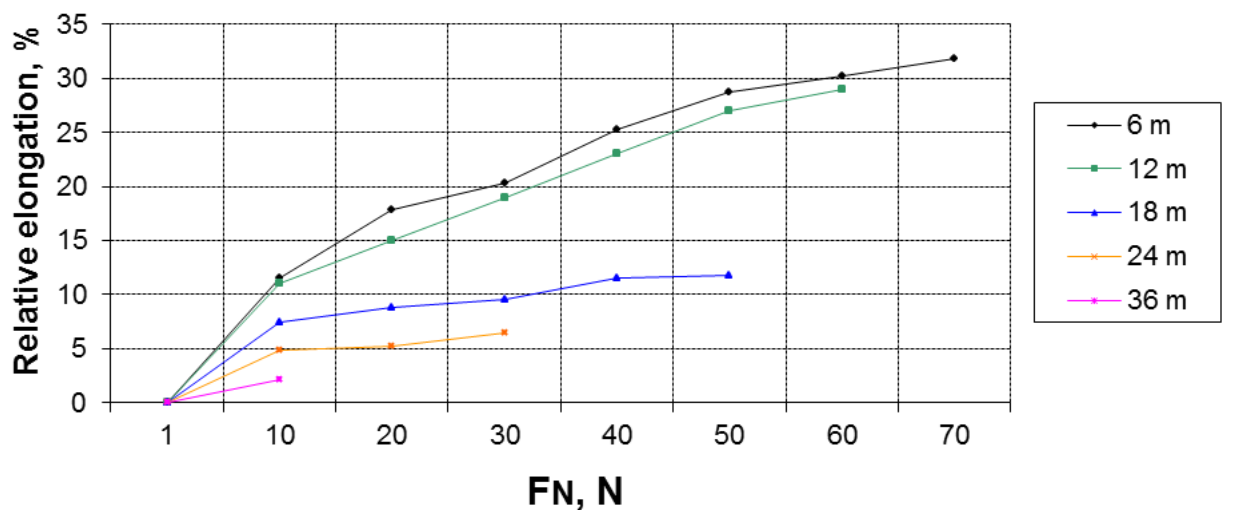

Source: Author

Figure 7: Male and female blood-vessel strength as relative value dependent on age (in months)

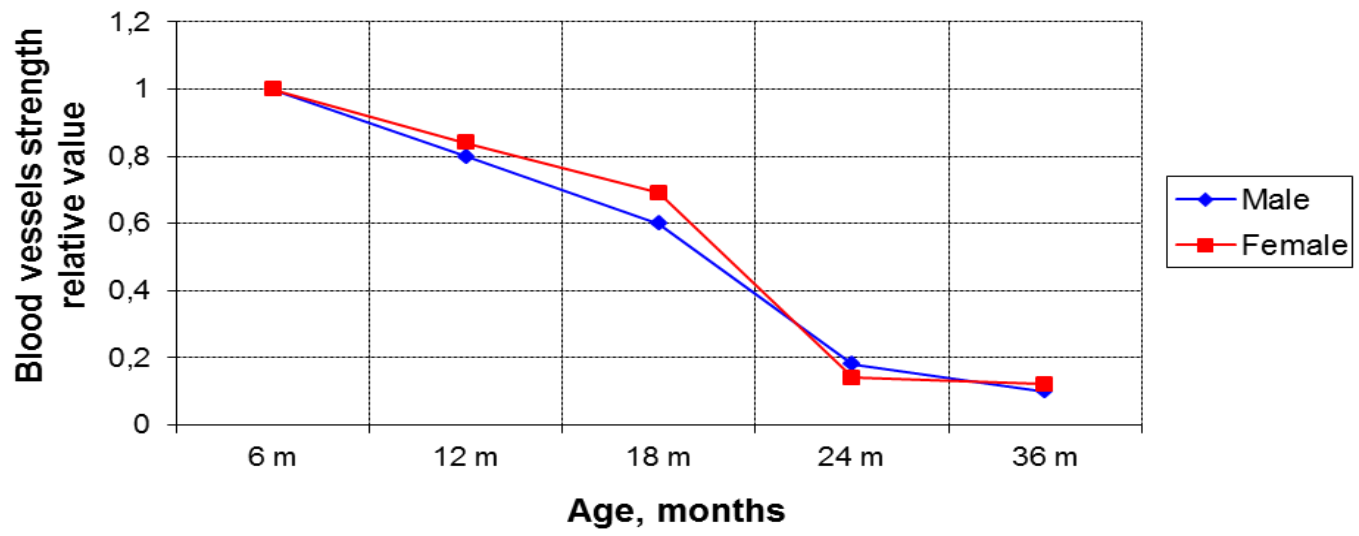

Source: Author

\section{Conclusion}

The created blood vessel model, which evaluated blood vessel pathologies, provided the following outcomes:

- Blood flow velocity in the pathologic blood vessel was from 1.4 to 2.2 times greater than that in a healthy blood vessel, depending on the blood pressure and the degree of pathology;

- Double symmetrical blood vessel stenosis was the cause of fissures related to stresses in pathologic regions, which increased up to 13.8 times, and to blood pressure, which increased 3.4 times; and

- Blood vessel fissures may occur due to local blood pressure rather than systolic blood pressure.

The research results showed relative values of male and female blood-vessel strength that decreased with increasing age. Possibly, gender difference does not have a major impact on strength, whereas age difference has a greater influence on strength of blood vessels because with aging this study indicated that such strength can decrease up to 9 times.

\section{References}

Balázs, T., Bognár, E., Zima, E., \& Dobránszky, J. (2008). Mechanical properties of coronary vein - In vitro evaluation of longitudinal and transversal samples. MAGYAR BIOMECHANIKAI KONFERENCIA - A-0032. 24-32.

Birgit Kantor, M. D., Eike Nagel, M. D., Paul Schoenhagen, M. D., Jörg Barkhausen, M. D., Thomas, C., \& Gerber, M. D. (2009). Coronary Computed Tomography and Magnetic Resonance Imaging. Curr Probl Cardiol, 34(4): 145-217. DOI:

10.1016/j.cpcardiol.2008.12.002 
Cecelja, M, \& Chowienczyk, P. (2012). Role of arterial stiffness in cardiovascular disease. Journal of the Royal Society of Medicine Cardiovascular Disease, 1:11. DOI 10.1258/cvd.2012.012016

Hyun Soo Kim, M. D., Kyoung, I. \& Cho, M. D. (2013). Association of Carotid Artery Parameters of Atherosclerosis in Coronary Artery Disease. Journal Cardiovsc Ultrasound, 21 (2): 72-80.

Lantz, J., Renner, J., \& Karlsson, M. (2011). Wall shear stress in a subject specific human aorta - Influence of fluid-structure interaction. International Journal of Applied Mechanics, (3), 4, 759-778. http://dx.doi.org/10.1142/S1758825111001226

Laucevičius, A., Rinkūnienė, E., Skorniakov, V., Petrulionienė, Ž., Kasiulevičius, V., Jatužis, D., Ryliškytè, L., Badarienė, J., Klumbiené, J., Šlapikas, R., \& Kizlaitis, R. (2013). High-Risk Profile in a Region with Extremely Elevated Cardiovascular Mortality. Hellenic Journal of Cardiology, 54: 441-447.

Long, Q. (2001). Numerical Investigation of Physiologically Realistic Pulsatile Flow Through Arterial stenosis, Journal of Biomechanics, 34: 1229-1242.

Mandal, P. K. (2005). An Unsteady Analysis of Non-Newtonian Blood Flow through Tapered Arteries with a Stenosis, International Journal of Non-Linear Mechanics, 40: 151-164.

Mariūnas, M., \& Uzdilaite, G. (2006). Reserch on the Influence of Pathology Level to Stresses in Elastic Arterines. Journal of Vibroengineering, Vol.8, No 3, 30-34.

Mariūnas, M., \& Kuzborska, Z. (2011). Pressure dynamics of blood vessels when modeling pathological processes, J. of Vibroengineering, 13(2), 269-275.

Mariūnas, M., Kuzborska, Z., \& Šešok, A. (2013). Research of pathology degree and kind influence on the stress in damaged blood vessels areas. Journal of Vibroengineering, Vol. 15 Issue 4, 2029-2034.

Meola, M, \& Petrucci, I. (2008). Color Doppler sonography in the study of chronic ischemic nephropathy. Journal of Ultrasound, 11(2): 55-73.

Michlek, E., Zyra, A., \& Lagan, S. (2013). Current Problems of Biomechanics. The study of mechanical properties of artificial blood vessels, Vol. 7, 99-104.

Milnor, W. R. (2009). Hemodynamics. Williams and Vilkins, 413-419.

Panniera, B. M., Avolio, A. P., Hoeksc, A., Mancia, G., \& Takazawa, K. (2002). Methods and devices for measuring arterial compliance in humans, Am J Hypertens, Vol. 15, Issue 8, 743-753.

Petrulionienè, Ž., \& Apanavičienè, D. A. (2010). Evaluation of arterial hypertension control and treatment in daily practice of family physicians. Medicina (Lithuania), 46(10):657-663.

Pickering, T. G. (2002). Principles and techniques of blood pressure measurement, Cardiology Clinics, Vol. 20, Issue 2, 207 223.

Roger, V. L., Go, A. S., Lloyd-Jones, D. M., Benjamin, E. J., Berry, J. D., Borden, W. B., Bravata Dawn, M., Dai, S., Ford, E. S., Fox, C. S., Fullerton, H. J., Gillespie, C., Hailpern, S. M., Heit, J. A., Howard, V. J., Kissela, B. M., Kittner, S. J., Lackland, D. T., Lichtman, J. H., Lisabeth, L. D., Makuc, D. M., Marcus, G. M., Marelli, A., Matchar, D. B., Moy, C. S., Mozaffarian, D., Mussolino, M. E., Nichol, G., Paynter, N. P., Soliman, E. Z., Sorlie, P. D., Sotoodehnia, N., Turan, T. N., Virani, S. S., Wong, N. D., Woo, D., \& Turner, M. B. (2012). Executive summary: heart disease and stroke statistics - 2012 update: a report from the American Heart Association, 125(1):188-97. http://dx.doi.org/10.1161/CIR.0b013e3182456d46irculation.

Rosamond, W., Flegal, K., Friday, G., Furie, K., Go, A., Greenlund, K., Haase, N., Ho, M., Howard, V., Kissela, B., Kittner, S., Lloyd Jones, D., McDer-mott, M., Meigs, J., Moy, C., Nichol, G., O’Donnell, C. J., Roger, V., Rumsfeld, J., Sorlie, P., Steinberger, J., Thom, T., Wasserthiel-Smoller, S., \& Hong, Y. (2007). Heart disease and stroke statistics - 2007 update: a report from the American Heart Association Statistics Committee and Stroke Statistics Subcommittee. Circulation, 115(5): 69-171. http://dx.doi.org/10.1161/CIRCULATIONAHA.106.179918

Steele, B. N., Wan, J., Ku, J. P., Hughes, T. J., \& Taylor, C. A. (2003). In Vivo Validation of a One-Dimensional FiniteElement Method for Predicting Blood Flow in Cardiovascular Bypass Grafts, IEEE Trans Biomed Eng., 50(6), 649-656. Taylor, C. A., \& Draney, M. T. (2004). Experimental and Computational Methods in Cardiovascular Fluid Mechanics, Annual Review of Fluid Mechanics, Vol. 36, 197-231.

Taylor, C. A., \& Steinman, D. A. (2005). Flow Imaging and Computing: Large Artery Hemodynamics, Annals of Biomedical Engineering, 33(12), 1704-1709.

Vignon, I., \& Taylor, C. A. (2004). Outflow Boundary Conditions for One-Dimensional Finite Element Modeling of Blood Flow and Pressure Waves in Arteries, Wave Motion, 39(4), 361-374.

Vignon-Clementel, I. Figueroa, C. A., Jansen, K. E., \& Taylor, C. A. (2010). Outflow boundary conditions for 3D simulations of non-periodic blood flow and pressure fields in deformable arteries, Computer methods in Biomechanics and Biomedical Engineering, 13, 5, p. 625-640.

Wang, J. J., \& Parker, K. H. (2004). Wave propagation in a model of the arterial circulation, J Biomech, 37(4), 457-470. 